\title{
PERANCANGAN SISTEM APLIKASI INVENTORY DAN PENJUALAN DI DISTRO SIXTEEN MERCH BERBASIS JAVA
}

\author{
Rio Pratomo \\ Program Studi Informatika, Fakultas Teknik dan Ilmu Komputer, Universitas Indraprasta PGRI \\ Jalan Raya Tengah No 80, Kelurahan Gedong, Pasar Rebo, Jakarta Timur \\ Pratomobnc@gmail.com
}

\begin{abstract}
Abstrak
Sistem inventory dan penjualan adalah sebuah hal yang penting dalam suatu perusahaan, maka harus diatur secara efektif dan efisien. Tujuan penelitian ini adalah menganalisa sistem yang sedang berjalan pada Distro Sixteen Merch. Metode penelitian yang digunakan adalah Metode Research and Development (R\&D). Selain itu peneliti juga menggunakan metode wawancara dan kepustakaan untuk mendapatkan data lebih lengkap. Adapun manfaatnya untuk memudahkan perusahaan dalam mengelola data produk yang ada, memanfaatkan produk, dan membantu pengambilan keputusan terhadap kebutuhan produk yang ada. Kesimpulan penelitian ini adalah dengan diterapkannya aplikasi sistem inventory dan penjualan pada perusahaan, menjadikan lebih baik dan terstruktur.
\end{abstract}

Kata Kunci : Inventory, Perancangan, Sistem, Metode $R \& D$.

\begin{abstract}
Inventory and sales system is an important thing in a company, it must be managed effectively and efficiently. The purpose of this research is to analyze the running system on the Sixteen Merch Distro. The research method used is the Research and Development $(R \& D)$ method. In addition, researchers also use interview methods and libraries to get more complete data. The benefit is to facilitate the company in managing existing product data, utilizing products, and helping decision making to the needs of existing products. The conclusion of this research is the application of inventory system and sales of the company, making it better and structured.
\end{abstract}

Keywords: Inventory, Design, System, R\&D Method.

\section{PENDAHULUAN}

Salah satu contoh pemanfaatan teknologi informasi dibidang komputer yaitu penggunaan program sistem informasi yang berupa input proses lalu output serta laporan rinci dari penginputan program tersebut. Pengertian dari program sistem informasi itu sendiri adalah suatu bentuk sarana pendukung untuk merekap data serta dapat menampilkan suatu bentuk laporan dari rekapan data tersebut lengkap dengan tanggal serta waktu pada saat penginputan data tersebut. Di suatu perusahaan apabila sudah menggunakan metode ini maka akan membantu proses dari kinerja perusahaan yang telah dijalankan. Bagi perusahaan-perusahaan yang didirikan oleh suatu pihak pemerintah atau swasta seperti halnya Distro Sixteen Merch yang bergerak pada bidang penjualan fashion seperti pakaian, jaket, dan topi, yang berlokasi di kota Depok. Hal yang menjadi kendala pada Distro Sixteen Merch adalah pendataan pada bagian persediaan barang dan penginputan data transaksi penjualan yang masih dilakukan dengan cara manual. Distro Sixteen Merch bertujuan menghasilkan informasi dan laporan mengenai hal-hal yang berkaitan dengan transaksi penjualan barang. Informasi maupun laporan yang dihasilkan dari proses pengolahan data yang berjalan saat ini diantaranya berupa transaksi penjualan barang, pengolahan data yang dilakukan pegawai saat ini masih memiliki beberapa kekurangan dan tidak efisien. Diantaranya masih menggunakan laporan penjualan dan pembelian barang dengan cara manual, sehingga terjadi keterlambatan informasi dan kesalahan data informasi. Salah satu faktor terjadinya kesalahan pengolahan data barang dan data transaksi penjualan barang menggunakan data yang terpisah sehingga sering terjadi perbedaan data. 


\section{PENELITIAN RELEVAN}

Penelitian oleh Yanah Nursolehah Hasanah (2013) dengan judul Perancangan Sistem Pengadaan Barang di Labolatorium Gunung Sahari. Hasil Penelitian tersebut adalah aplikasi pengadaan barang yang dapat memaksimalkan kinerja laboratorium dalam mengolah data-data dalam setiap prosesnya. Penelitian oleh Angelina Permatasari (2015) dengan judul Perancangan Sistem Informasi Penjualan pada Toko Kue. Hasil dari penelitian tersebut adalah rancangan sistem Informasi Penjualan pada Toko Kue yang dapat mempermudah staff dalam mengelola data-data penjualan.

\section{METODE PENELITIAN}

\section{Teknik Pengumpulan Data}

Metode penelitian yang digunakan yaitu metode Research and Development ( $R \& D$ ). Metode $R \& D$ merupakan metode penelitian yang digunakan untuk menghasilkan produk tertentu dan menguji keefektifan metode tersebut. Metode $R \& D$ ini seringkali digunakan sebagai proses penelitian yang bertujuan untuk menghasilkan produk, yang langkah-langkahnya adalah analisis, perancangan, penerapan, dan pemeliharaan. Metode pengumpulan data yang dilakukan oleh peneliti untuk mendapatkan data-data serta informasi untuk mendukung penyempurnaan hasil dari penelitian ini antara lain :

\section{a. Observasi}

Pengumpulan data dengan melakukan pengamatan secara langsung terhadap objek penelitian, mencatat hal-hal penting khususnya data inventori dan pemesanan bahan kimia.

b. Studi Pustaka

Pengumpulan data dengan mengumpulkan sumber-sumber tertulis, dengan cara membaca, mempelajari, dan mencatat hal-hal penting yang berhubungan.

c. Wawancara

Wawancara dilakukan dengan melakukan komunikasi dan wawancara secara langsung dengan pihak perusahaan.

\section{Langkah-langkah Pengembangan Sistem}

Tahapan-tahapan dari paradigma waterfall dapat yaitu sebagai berikut (H. Larasati and S. Masripah, 2017) :

a. Persiapan Data

Mengumpulkan data kebutuhan seluruh elemen sistem seperti data-data yang digunakan. Dimana elemen-elemen tersebut dapat menunjang dalam pelaksanaan proyek.

b. Analisis data dan Proses

Melakukan pengumpulan data dengan berfokus pada perangkat lunak, meliputi informasi, fungsi masing-masing bagian sistem, kerja atau cara kerja, dan antar muka.

\section{c. Perancangan}

Merancang struktur data, arsitektur perangkat lunak, rincian procedural, dan karakteristik antar muka.

\section{d. Pengkodeam}

Tahapan untuk membuat suatu kode tentang aplikasi yang akan dibuat agar dapat dibaca dan diterjemahkan oleh komputer.

e. Pengujian

Memastikan semua fungsi sistem bekerja dengan baik dan menjamin kualitas aplikasi.

f. Implementasi dan Maintenance

Mengkoreksi dan memperbaiki kesalahan pada perangkat lunak yang baru diketahui pada saat perangkat lunak digunakan. 


\section{HASIL DAN PEMBAHASAN}

\section{Diagram Alir Data (DAD) Sistem Yang Berjalan}

Data Flow Diagram (DFD) adalah gambaran grafis yang memperlihatkan aliran data dari sumbernya dalam obyek kemudian melewati suatu proses yang mentransformasikan ke tujuan yang lain, yang ada pada objek lain.

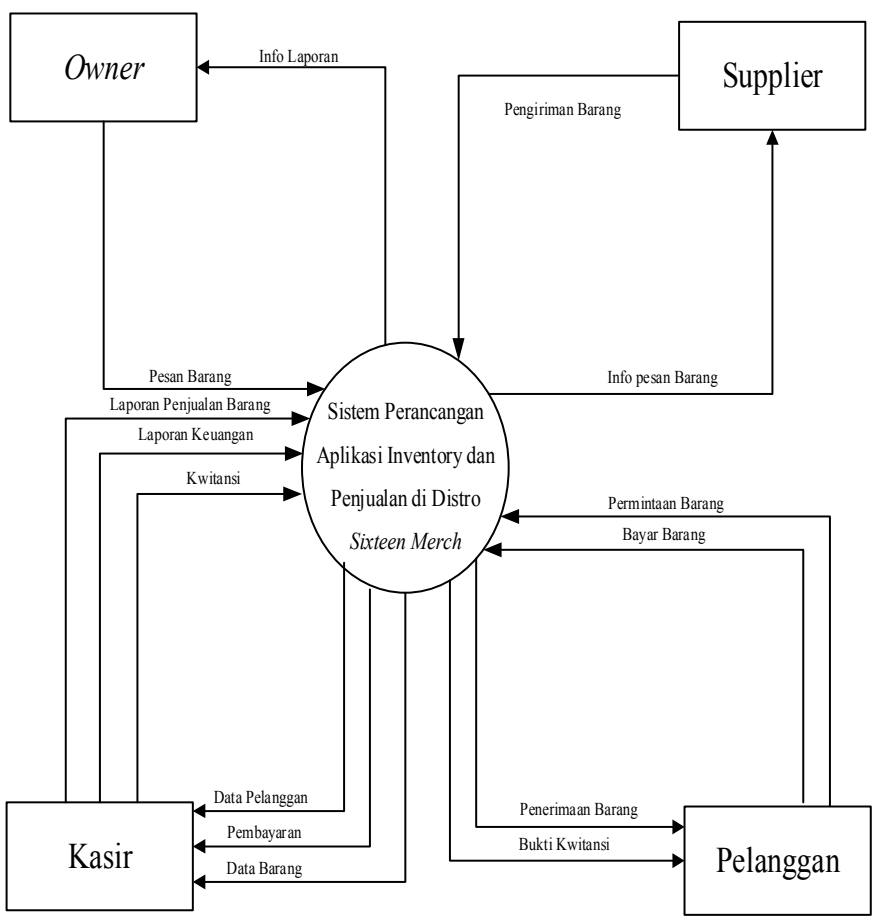

Gambar 1. Diagram Konteks Sistem Berjalan

\section{Analisis Permasalahan}

Dari hasil penelitian yang peneliti lakukan maka peneliti dapat menganalisa permasalahan yang ada pada sistem perancangan pemesanan dan penjualan Distro Sixteen Merch yaitu:

a. Proses penjualan yang masih belum terkomputerisasi, sehinngga dalam pembuatan tanda bukti penjualan masih manual.

b. Proses penjualan yang belum menggunakan sistem yang baik sehingga menyebabkan lambatnya pekerjaan kasir dalam penghitungan pembelian barang sehingga belum efektif dan efesien.

c. Kurangnya sumber daya manusia yang memahami sistem koputerisasi menjadi suatu penyebab belum dibuatnya sistem perancangan pemesanan dan penjualan Distro Sixteen Merch.

\section{Alternatif Penyelesaian Masalah}

Berdasarkan masalah-masalah yang dibagi dalam pemesanan dan penjualan pada Distro Sixteen Merch maka peneliti memberikan alternatif penyelesaian masalah. Merancang sebuah sistem secara terkomputerisasi sehingga memudahkan dalam proses pemesanan dan penjualan barang di Distro Sixteen Merch. Merancang sebuah sistem inventory dan penjualan, sehingga inventory dan penjualan dapat dilaksanakan lebih efektif dan efesien. Perancangan database untuk aplikasi penjualan sehingga penyimpanan data barang dan penjualan tidak mengguakan media kertas atau arsip lagi melainkan database yang sudah menginput dan menampilkan saja. 


\section{Diagram Alir Data (DAD) Sistem Yang Diusulkan}

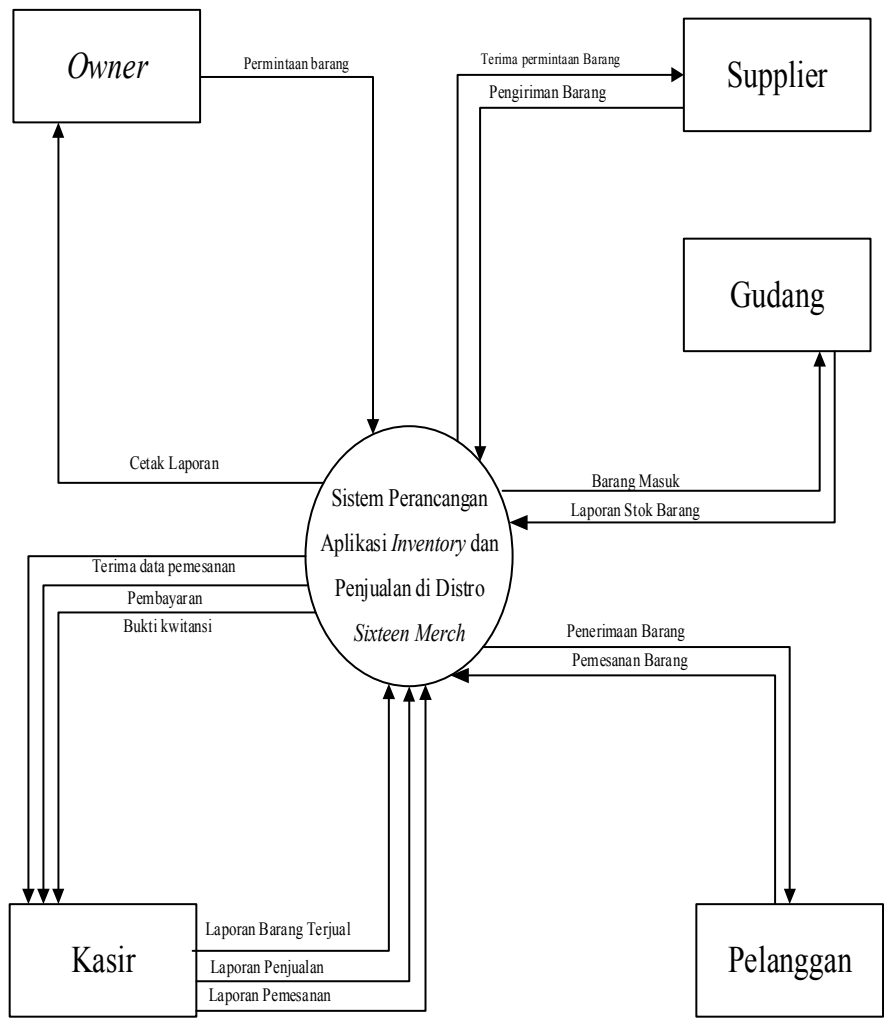

Gambar 2. Diagram Konteks Sistem Yang Diusulkan

Normalisasi Bentuk Ke-2 (NF)

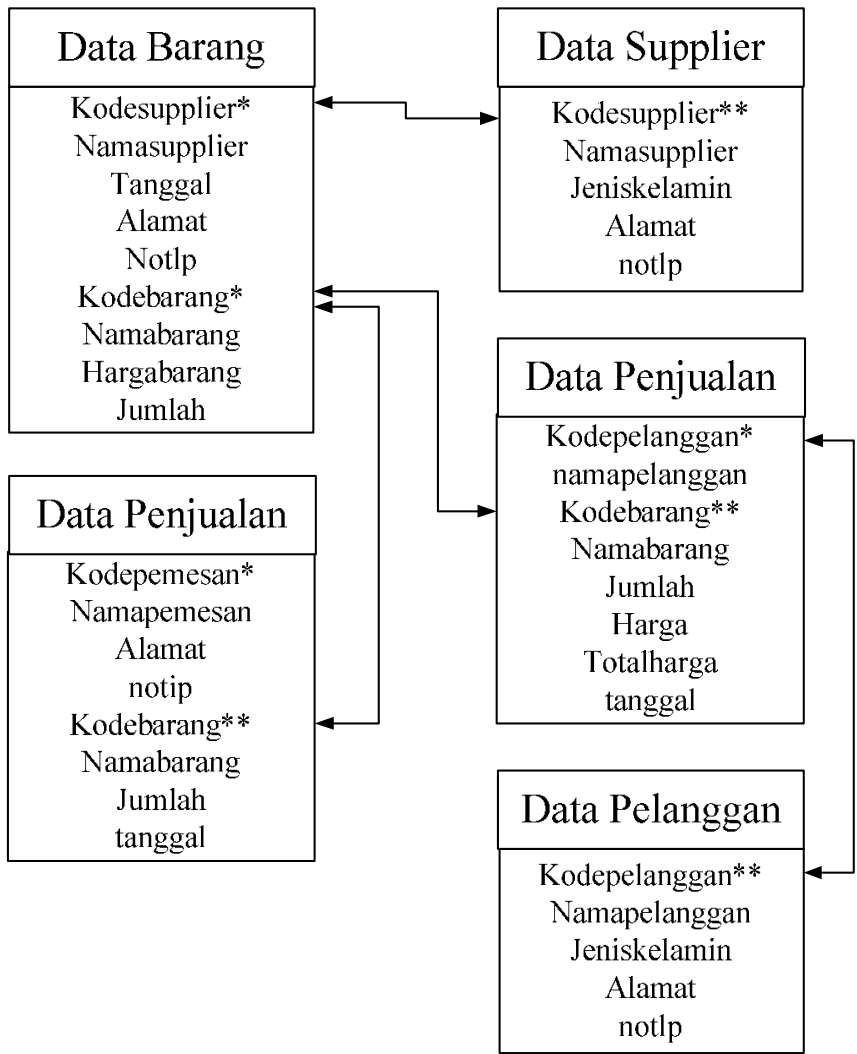

Gambar 3. Normalisasi Bentuk Ke-2 (NF) 


\section{Sistem Perancangan Aplikasi Inventory dan Penjualan di Distro Sixteen Merch Berbasis Java}

Sistem perancangan aplikasi inventory dan penjualan di Distro Sixteen Merch berbasis java, aplikasi ini dibangun dengan bahasa pemrograman Java. Java adalah bahasa pemrograman yang portable karena dapat dijalankan pada berbagai sistem operasi.

\section{Tampilan Login}

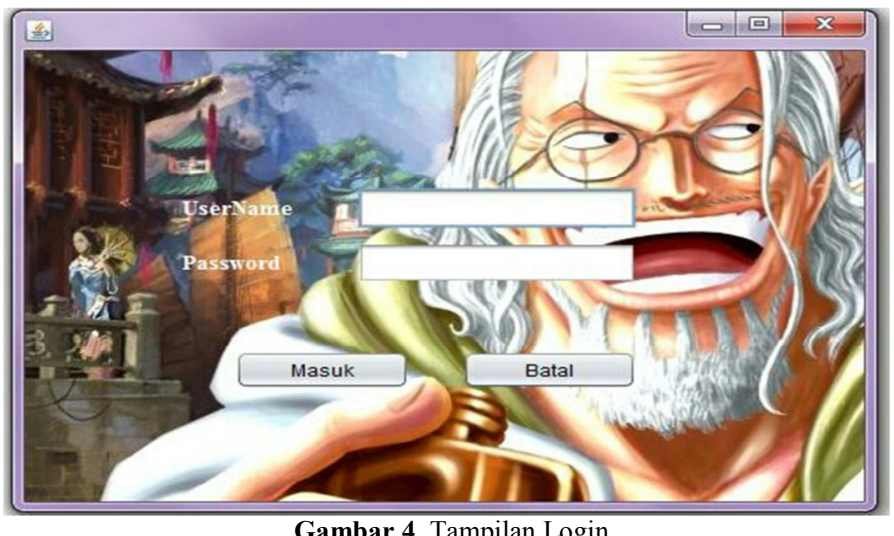

Tampilan From Masukan login merupakan tampilan awal dalam aplikasi ini, di sini UserName(pengguna) di mana memasukan UserName dan Password agar biasa masuk ke menu selanjutnya untuk menggunakan aplikasi ini.

\section{Tampilan Data Form Stok Barang}

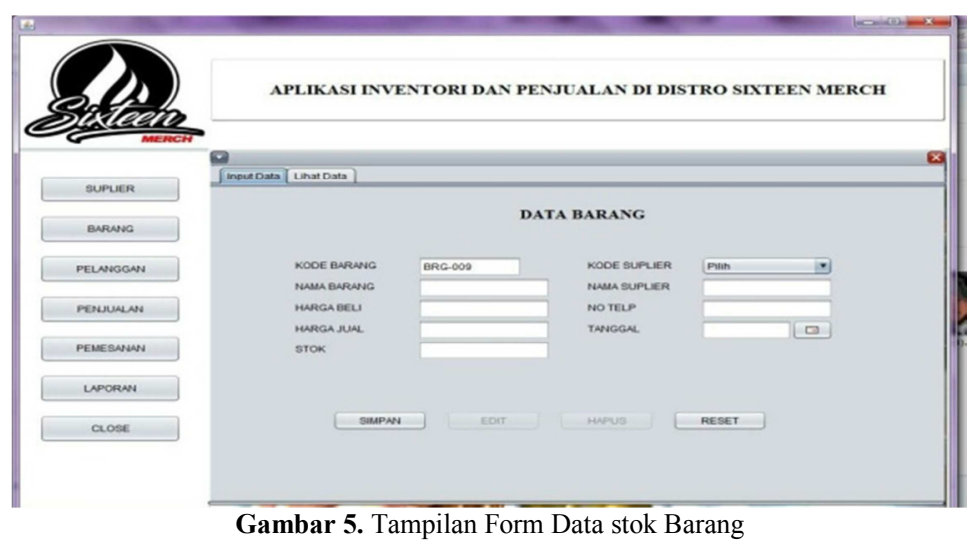

Tampilan data barang, berfungsi untuk memasukan data-data barang masuk dari supplier. Data barang berisi kode barang, nama barang, harga beli, harga jual, stok, kode supplier, nama supplier, no telp, dan tanggal.

\section{Tampilan Form Data Penjualan}

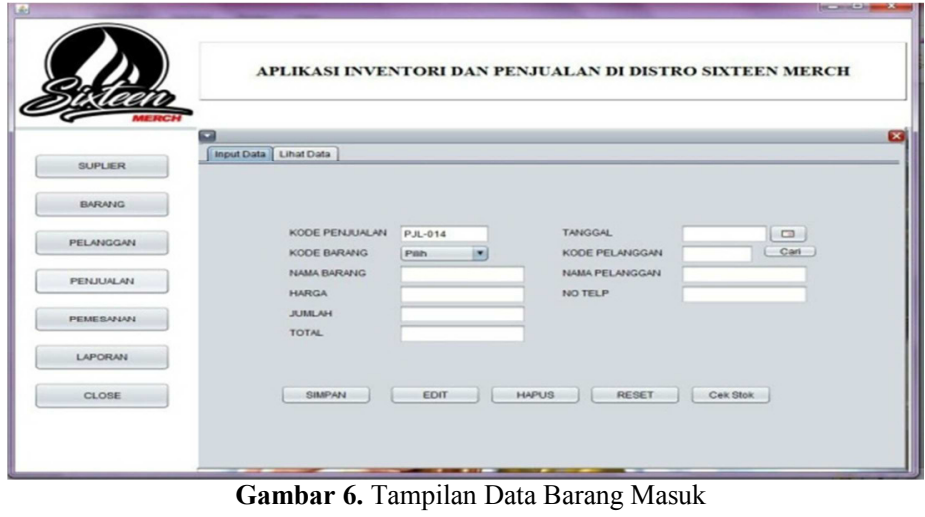


Tampilan data penjualan, berfungsi untuk melakukan transaksi antara admin (kasir) dengan pelanggan yang ingin membeli barang. Data penjualan berisi kode penjualan, kode barang, nama barang, harga, jumlah, total, tanggal, kode pelanggan, nama pelanggan, dan no telp.

\section{Tampilan Form Data Pemesanan}

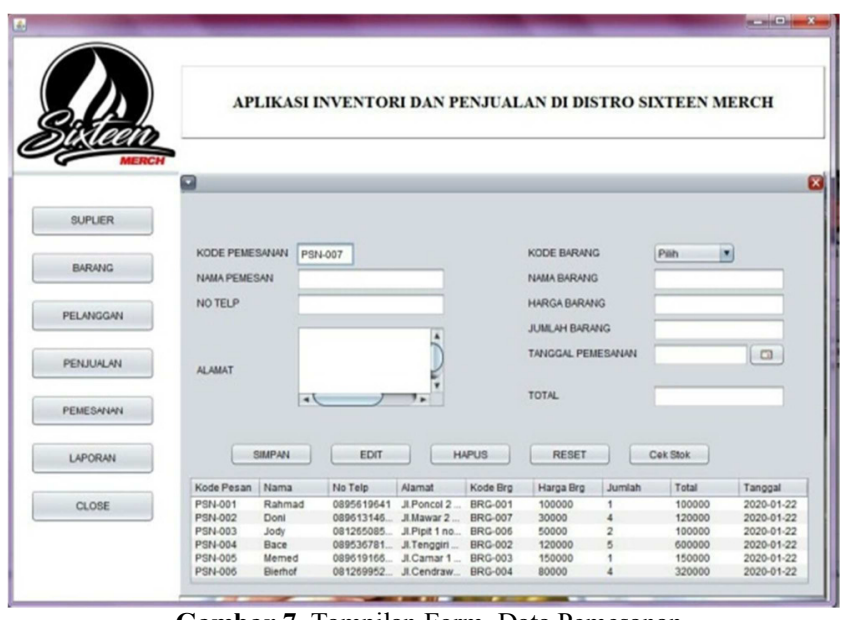

Gambar 7. Tampilan Form Data Pemesanan

Tampilan data pemesanan, berfungsi untuk pemesanan barang apabila pembeli melakukan permintaan pemesanan barang kepada admin (kasir).

\section{Tampilan Form Kwitansi Pembelian Barang}

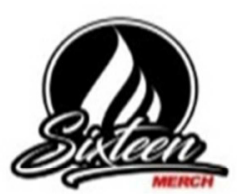

\section{KWITANSI PEMBELIAN BARANG}

JL. Kutilang 3, RT 05/Rw. 02, kelurahan Depok Jaya, kecamatan Pancoran Mas kota Depok. 16432.

No Faktur : PJL-018 Pembeli: Bace

\begin{tabular}{|c|c|c|c|c|}
\hline Kode Barang & Nama Barang & Harga & Jumlah & Total \\
\hline BRG-006 & Boxer & 50000 & 5 & 250000 \\
\hline
\end{tabular}

Depok, Rabu 22 Januari 2020

$$
\text { Admin }
$$

Rahman Zakaria

Gambar 8. Tampilan Form Kwitansi Pembelian Barang

Tampilan form kwitansi pembelian barang, berfungsi untuk bukti pembayaran yang dilakukan oleh pelanggan. Kwitansi ini berisi no faktur, nama pembeli, kode barang, nama barang, harga, jumlah, dan total. 


\section{Tampilan Laporan Data Penjualan}

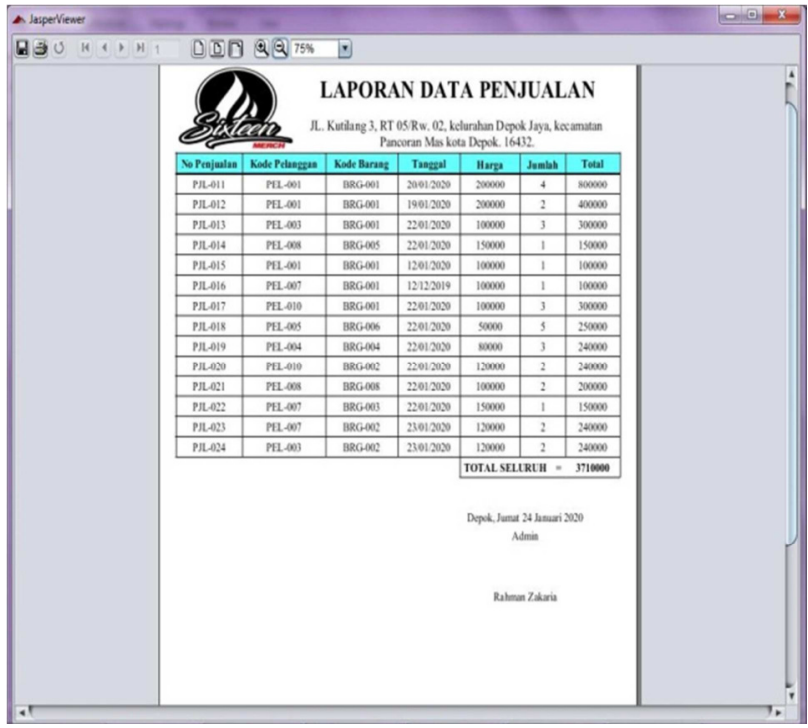

Gambar 9. Tampilan Laporan Data Penjualan

Tampilan form Laporan Data penjualan, berfungsi untuk melaporkan data penjualan kepada owner distro. Laporan data penjualan berisi no penjualan, kode pelanggan, kode barang, tanggal, harga, jumlah, total dan total seluruh. telah dicetak.

\section{Tampilan Laporan Data Barang}

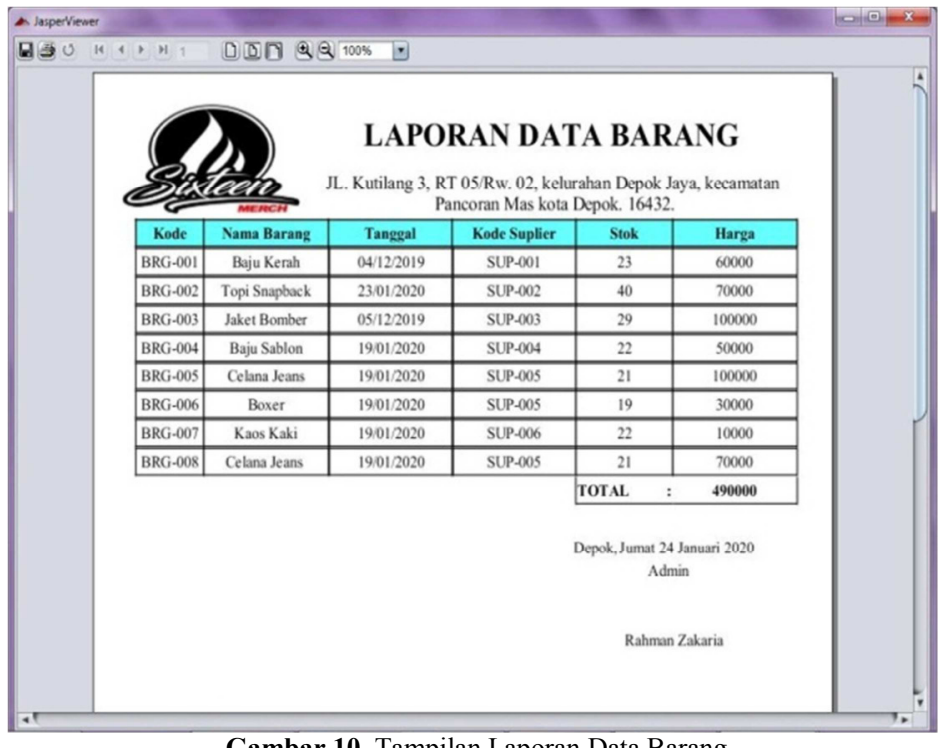

Tampilan laporan data barang, berfungsi untuk melaporkan kepada owner distro. Laporan data barang berisi kode, nama barang, tanggal, kode supplier, stok, harga, dan total. 


\section{SIMPULAN}

Dalam hal ini peneliti menyampaikan pokok bahasan penelitian, adapun simpulan-simpulan yang disusun oleh peneliti yaitu. Sistem yang dibangun ini dapat mempermudah dalam proses pendataan barang masuk dan keluar yang sudah tersistem sehingga lebih mudah dalam pencarian data yang diperlukan dan dengan adanya sistem inventory ini dapat mengurangi penumpukan kertas. Untuk proses pemesanan barang yang dilakukan oleh pelanggan bisa dilakukan secara online melalui website yang telah disediakan dengan cara pelanggan harus mendaftar terlebih dahulu untuk bisa memesan barang. Setelah terdaftar pelanggan bisa memesan barang dan kemudian melakukan konfirmasi pembayaran melalui nomer rekening yang tertera di website agar barang bisa segera dikirim ke alamat tujuan pelanggan. Sistem informasi inventory yang dibangun dapat mendata transaksi pemesanan, pengiriman, barang masuk dan keluar dan transaksi pembayaran yang sudah terkomputerisasi dan dengan adanya laporan dan grafik sehingga dapat mengetahui dan memberikan informasi yang cepat, tepat, dan akurat setiap harinya.

\section{DAFTAR PUSTAKA}

A. Kristanto. (2013). Perancangan Sistem Informasi dan Aplikasinya.

J. Broad. (2009). "Research and Development (R\&D)," in Risk Management Framework

Jogiyanto. (2009). "Analisis dan Desain," Yogyakarta Andi.

H. Larasati and S. Masripah. (2017). "ANALISA DAN PERANCANGAN SISTEM INFORMASI PEMBELIAN GRC DENGAN METODE WATERFALL," None.

Nofriadi. (2015). Java Fundamental Dengan Netbeans 8.0.2. 